\title{
Study and characterization of the micellar phase of the polyethylene glycol 40 stearate, water, and soy lecithin system
}

\author{
Mercedes Díaz-Lagos¹, Gemma Montalvo-García², Mercedes Valiente-Martínez², Segundo Agustín Martínez-Ovalle,* \\ ${ }^{1}$ Grupo de Ingeniería Geológica, Universidad Pedagógica y Tecnológica de Colombia, Sogamoso, Colombia \\ ${ }^{2}$ Department of Analytical Chemistry, Physical Chemistry, and Chemical Engineering, Universidad de Alcalá, Alcalá de Henares, Spain \\ ${ }^{3}$ Grupo de Física Nuclear Aplicada y Simulación, Universidad Pedagógica y Tecnológica de Colombia, Tunja, Colombia
}

\begin{abstract}
Hydrophobically modified polymers (HMPs) have become of great importance as modifiers of rheological behavior, and as thickening agents for a great variety of products such as paints, foods, cosmetics, and medicines. HMPs are able to dissolve hydrophobic and hydrophilic molecules, just like surfactants. This means that HMPs combine the properties of surfactants and polymers. In this paper, the ability of HMPs to self-aggregate in water and in the presence of soy lecithin (a natural lipid which behaves as a dipolar surfactant) was studied. The characterization of the micellar phase of the soy lecithin/polyethelyne glycol 40 stearate (Acid S40P, nonionic)/water ternary system is presented by way of surface tension, optic microscope, and rheology methods. From the results, it is deduced that non-spherical micellar aggregates are formed, which orient in the direction of the flow under shear stress. Oscillation tests allowed for the determination that the viscous modulus G" is greater than the elastic modulus G', with behavior described by the Maxwell model. (C) 2016. Acad. Colomb. Cienc. Ex. Fis. Nat.
\end{abstract}

Key words: Lipids; Soy lecithin; Hydrophobically modified polymers; Surface tension; Optic microscope; Rheology.

Estudio y caracterización de la fase micelar del sistema formado a partir del polietilenglicol 40 estearato, agua y lecitina de soja

\begin{abstract}
Resumen
Los polímeros hidrofóbicamente modificados (PHM) han adquirido una gran importancia como modificadores de comportamiento reológico, agentes espesantes en una gran variedad de productos como son pinturas, alimentos, cosmética o medicamentos. Estos polímeros PHM tiene la capacidad de solubilizar moléculas hidrofóbicas al igual que los tensioactivos. Es decir, los PHM combinan las propiedades de los tensioactivos y de los polímeros. En este trabajo en general se estudiará la capacidad de los PHM de autoagregarse y comportarse como tensioactivos. Se presenta el estudio de la fase micelar del sistema ternario lecitina de soja (lípido natural que se comporta como tensioactivo doblemente iónico)/ polietilenglicol 40 estearato (Acid S40P, no iónico)/agua. La caracterización se realiza mediante los métodos de tensión superficial, microscopia óptica y reología. De los resultados se deduce que se forman agregados micelares no esféricos que se orientan en la dirección del flujo bajo los esfuerzos de cizalla. Los ensayos de oscilación permitieron determinar que el modulo viscoso $\mathrm{G}^{\prime \prime}$ es superior al elástico $\mathrm{G}^{\prime}$, con un comportamiento descrito por el modelo de Maxwell de un elemento. (C) 2016. Acad. Colomb. Cienc. Ex. Fis. Nat.

Palabras clave: Lípidos; Lecitina de soja; Polímeros hidrofóbicamente modificados; Polietilénglicol 40 estearato; Reología.
\end{abstract}

\section{Introduction}

The interaction between surfactants and polymers in solutions has received much attention due to the numerous applications ranging from pure science to everyday life and industry (e.g. pharmaceuticals, biomedical applications, detergents, oil recovery, paints, foods, and mineral processing) (Goddard \& Ananthapadmanaban, 1993; Kwak, 1998; Jonsson, et al., 1998).

Amphiphilic molecules such as lipids or surfactants spontaneously form a great variety of stable structures with their corresponding properties. The control of said supramolecular structures at a microscopic level, adjusting for the different intermolecular interactions that are responsible for their arrangement, leads to a broad range of different microscopic properties of the material. This is particularly important for the application of multifunctional devices, but requires a complete understanding of the transformation mechanisms of the structures involved in order to take complete advantage of their nature to create a variety of new functional materials (Koynova \& Tenchov, 2001).

\footnotetext{
*Corresponding author:

Segundo Agustín Martínez-Ovalle, s.agustin.martinez@gmail.com

Recibido: 04 de abril de 2016

Aceptado: 20 de mayo de 2016
} 
In aqueous solutions, amphiphilic molecules form micelles. These are generally spherical structures where the polar groups are on the surface and the non-polar parts remain immersed on the inner side of the micelle. In nonpolar structures, reverse micelles are formed, with their hydro-phobic groups on the exterior. Polymeric micelles are formed by chains of polymers made up of hydrophilic and hydrophobic parts separated in blocks. Surfactants have the ability to modify the surface tension of the solutions to which they are added, and at a certain concentration they begin to form molecular aggregates known as micelles. The formation of micellar aggregates begins to occur at the critical micelle concentration, or CMC, whose value can be determined using surface tension measurements. The critical micelle concentration (CMC) is the concentration at which micelles begin to form, and it is a characteristic of every amphiphilic system. The lower the $\mathrm{CMC}$, the more stable the micelles are at lower concentrations of amphiphiles in the medium. For double-chain lipids and amphiphilic molecules, the formation of lamellar phases (bilayers of surfactants separated by layers of water) is preferred to micelles. They can have an open and extended bilayer structure, or enclosed bilayers forming vesicles or liposomes.

Polyethylene glycol (PEG) is a frequently used polymer, as it is highly soluble and a good stearic protector of microparticles in biological media due to its biocompatibility. In many cases, PEG is modified by grafting hydrophobic molecules of cosmetic or pharmaceutical interest (such as certain antibiotics) to its polymer chain, which also facilitate the formation of micelles (Torchelin, 2002). Although composites derived from PEG are widely used in mixtures with lipids, the nature of the interactions between the lipids and polymers are unknown, and in some cases present contradictory results. Through previous research, it is known that the presence of polyethylene glycol of different molecular weights (PEG-6000 or PEG-2000) does not significantly affect the interactions between water molecules and the choline groups of lecithin (Khan, et al., 1994). Nevertheless, other authors suggest that the presence of PEG-8000 induces the dehydration of the polar head of the phospholipids due to changes in the size and shape of the phospholipid vesicles (Bartucci, et al., 1996). When PEG is grafted onto the phospholipid chains, it results in improved stability of the liposomes that are formed (Nikolova \& Jones, 1998).

Polyethylene glycol 40 stearate (PEG 40 monostearate) is considered a nonionic surfactant and emulsifier for cosmetic formulations of the oil-in-water emulsion type, with a hydrophilic-lipophilic balance (HLB) of 16.9. It has also been used as a cosurfactant in solid lipid nanoparticles (Torchelin, 2002; Khan, et al., 1994; Bartucci, et al., 1996). Soy lecithin is also a phospholipid that is dipolar in nature (zwitterionic) and comes from natural sources. It is biodegradable, and does not present problems from a toxicology standpoint. For this reason, the system formed by both of these components is also environmentally friendly. This is of great interest for applications in the administration of pharmaceuticals (Torchelin, 2002; Khan, et al., 1994; Bartucci, et al., 1996). The advantages of using a derivative of polyethylene glycol (PEG), with its high hydrophilic nature, is that it is biologically inert and does not affect the other parts of the body (Nikolova \& Jones, 1998), though few studies have been conducted regarding the effects of PEG stearate in lipid formulations ( $\mathbf{L i}$, et al., 2008; Xia, et al., 2008; Xia, et al., 2009; Naumann, et al., 2001).

For these reasons, this paper centered on the rheological phase study of the micellar phase of the ternary soy lecithin/PEG 40 stearate/water system. Firstly, the binary PEG 40 monosterate/water system was characterized for the determination of the critical micelle concentration (CMC) and of its viscoelastic properties using rheology. The viscoelastic characterization of this system is of great interest, as the industrial process for manufacturing commercial products with these components implies the application of shear stress. The following observations were noted: the aggregation or phase behavior of the ternary system in the area of interest at lecithin contents of less than $20 \%$ by weight, and the viscoelastic behavior of the micellar phase, which is the only single-phased region that was formed in the area under study.

\section{Materials and methods}

Preparation of samples. The soy lecithin (Epikuron 200) was obtained from Degussa and was used without further purification. This lecithin is a mixture of phosphatidylcholines with fatty acid chains of varying lengths and degrees of unsaturation. The main component is linoleic acid, which has 18 carbons. The PEG 40 monostearate, known commercially as TEGO or Acid S40P (referred to hereinafter as S40P), was purchased from Goldschmidt $\mathrm{GmbH}$ of Essen, Germany. Its chemical structure $\left(\mathrm{CH}_{3}-\right.$ $\left.(\mathrm{CH} 2)_{16} \mathrm{CO}\left(-\mathrm{OCH}_{2} \mathrm{CH}_{2}\right)_{40}-\mathrm{OH}\right)$ shows that it is a hydrophobically modified PEG polymer and that it has surfactant properties due to a hydrophobic tail of 17 carbons (stearate) and a large hydrophilic head of 40 groups of poly (oxyethylene). The presence of groups not containing ethylene oxide was negligible.

All of the samples were prepared in deionized water and all of the appropriate quantities of each component were weighed in small flasks with screw caps. The system was homogenized using a Heidolph Reax 2000 test tube shaker. When a sample did not mix well at room temperature, it was gently heated to a temperature of no more than $60{ }^{\circ} \mathrm{C}$ to aid solubilization. Once the samples were ready, they were stored in a water bath at $30.0 \pm$ $0.1^{\circ} \mathrm{C}$ for the time necessary so that no changes in their appearance. Once thermodynamic equilibrium was reached at the desired temperature, the samples were visually analyzed. The presence of foam, precipitate, color, turbidity, 
transparency, homogeneity, or any other characteristic that presented itself was addressed. The optical birefringence was observed using crossed polarizers.

Surface Tension. The surface tension of the aqueous solutions of various concentrations of S40P was measured with a LAUDA TE-1C Tensiometer using the ring method. All measurements were carried out at $30.0 \pm 0.1{ }^{\circ} \mathrm{C}$, and each experiment was repeated multiple times, obtaining good reproducibility.

The surface excess concentration $\left(\Gamma_{2}\right)$ was estimated using the Gibbs adsorption isotherm equation (Eq. 1) and the hydrophilic surface area per molecule in the air-water interface using Eq. 2

$$
\begin{aligned}
\Gamma_{2} & =-\frac{1}{R T}\left(\frac{d \gamma}{d \ln C}\right) \\
a & =-\frac{10^{20}}{N_{A} \Gamma_{2}}
\end{aligned}
$$

$\mathrm{R}$ is the ideal gas constant $(\mathrm{J} / \mathrm{mol} \cdot \mathrm{K})$; $\mathrm{T}$ is the temperature in ${ }^{\circ} \mathrm{K}$; $\mathrm{C}$ is the concentration of the surfactant S40P in the solution; $\gamma$ is the surface tension of the solution in $\mathrm{N} / \mathrm{m} ; \mathrm{N}_{\mathrm{A}}$ is Avogadro's number; and is the hydrophilic surface area of the molecule expressed in $\mathrm{nm}^{2} /$ molecule.

Optic Microscope. The lamellar phases that form lipids demonstrate optical birefringence. The presence of these types of structures was studied using a Nikon Eclipse 50i optic microscope equipped with crossed polarizers and a Nikon Coolpix 8400 digital camera. These observations were carried out for a minimum of two months, as the state of the aggregation of the sample could have possibly changed in the time needed to reach thermodynamic equilibrium. The micellar samples are isotropic due to the crossed polarizers, and therefore cannot be observed using the polarizing optic microscope.

Rheology. To study the rheological behavior of the prepared systems, rheological experiments using the Carrimed CSL 100 rheometer were scheduled. The flow and the oscillatory behavior were measured using a cone and plate viscometer with a radius of $20 \mathrm{~mm}$ and an angle of 4: 0: 31 (deg: min: s). All measurements were made at $30.0 \pm$ $0.1{ }^{\circ} \mathrm{C}$. The temperature was maintained by a Peltier device in contact with a plate. A chamber was used to prevent evaporation of the sample during measurement. All of the results showed good reproducibility in the standard additions and in the oscillatory experiments, as well as in repetitions of the experiments using the same samples.

The flow curves were measured using the application of a series of increasing shear stresses for duration of two minutes spaced logarithmically. The viscosity $(\eta)$ was calculated by taking the quotient of the shear stress and the sheer rate.

The oscillatory experiments were performed under linear viscoelastic conditions, where deformation is independent of the shear stress applied. The angular frequency of oscillation $(\omega=2 \pi f)$ was varied from $0.1 \mathrm{a} 20 \mathrm{~Hz}$, at constant amplitude of oscillating shear stress. In the analysis of the micellar samples, the Maxwell model was applied (a spring and a damper connected in series). The dynamic properties of Maxwell materials can be represented by a linear differential equation whose solutions are:

$$
\begin{aligned}
G^{\prime} & =\frac{\eta \tau \omega^{2}}{1+(\tau \omega)^{2}} \\
G^{\prime \prime} & =\frac{\eta \omega}{1+(\tau \omega)^{2}}
\end{aligned}
$$

$\omega$ is the angular frequency and $\tau$ is the relaxation time. The storage modulus $G^{\prime}$ and the loss modulus $G^{\prime \prime}$ are the components of the complex modulus $G^{*}$ (the relaxation of the force amplitude and the deformation amplitude), and are related to the complex viscosity $\eta^{*}$ by Eq. 5 :

$$
\eta^{*}=\frac{\sqrt{\left[\left(G^{\prime}\right)^{2}+\left(G^{\prime \prime}\right)^{2}\right]}}{\omega}
$$

The Maxwell model predicts that at a high angular velocity, the value of the storage modulus will reach a plateau, while the loss modulus reaches a maximum. The inverse of the frequency at which $G^{\prime}$ and $G^{\prime \prime}$ intersect is the structural relaxation time.

\section{Results and discussion}

Determination of the critical micelle concentration (CMC). The CMC value of the binary Acid S40P/water system was determined to be the point of the sudden change in surface tension by plotting said value as a function of the logarithmic concentration of Acid S40P. In Figure 1, the CMC corresponds to the point of intersection of the regression lines in regions II and III. The CMC value obtained was $5.1 \times 10^{-5}$ $\mathrm{M}$, reaching a constant surface tension value of around 40 $\mathrm{mN} / \mathrm{m}$. Using the slope of the line segment found in region

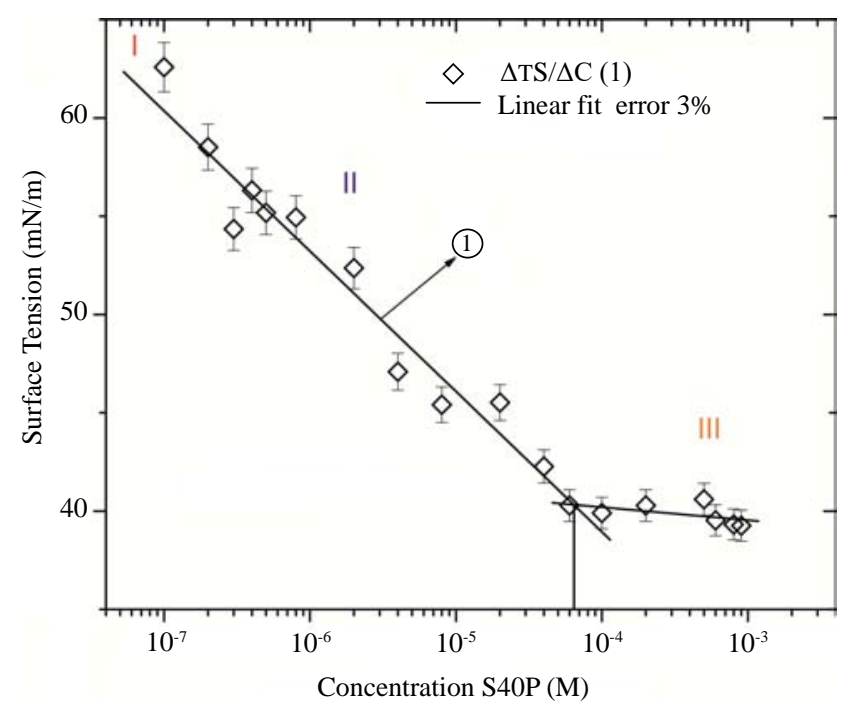

Figure 1. Change in surface tension as a function of the concentration of Acid S40P. The bars in the data indicate the measurement error. Least squares regression lines for regions II and III before and after the critical micelle concentration (the intersection of said regression lines) 
two of Figure 1, the excess surface tension was obtained $\left(\Gamma_{2}\right)$, which was estimated using the equation Gibbs adsorption isotherm equation (Eq. 1), giving a value of $1.24 \times 10^{-6}$ $\mathrm{mol} \cdot \mathrm{m}^{-2}$. This value corresponds to the hydrophilic surface area per molecule of the air-water interface of $1.4 \mathrm{~nm}^{2}$ (obtained using Eq. 2). This area per molecule is relatively large, and is consistent with the molecular structure of PEG 40 stearate, which can exert a lot of lateral pressure as a result of its large hydrophilic head with 40 groups of poly (oxyethylene).

Determination of phase behavior. The determination of the phase behavior was studied using two methods. The first of which consisted of the preparation of aqueous solutions with different concentrations of the polymer Acid S40P to observe and establish the solubility of this polymer in water (binary system). We call this system the Acid S40P/water system. The second method involved preparing solutions fixed Acid $\mathrm{S} 40 \mathrm{P} /$ lecithin ratios of $1.9,9$, and 20. In this manner, the areas of interest were delineated in the ternary phase diagram for the Acid S40P/ lecithin/water diagram.

The determination of the phases present in each sample was performed initially by direct visual observation. Using this method, the number of phases present in each sample vial was determined, as well as the turbidity or transparency and fluidity or isotropic nature of each sample using crossed polarizers. This allowed for the delineation of the areas shown in Figure 2 in magenta, blue, and green.
In the diagram, the magenta area corresponds to the area that is rich in water, where a region of emulsions appears, which are separated into two phases, resulting in a white precipitate on the bottom and an isotropic solution above it. This separation occurred in less than a week, and said area was not studied in detail. The area shown in blue extends across the binary water/Acid S40P axis, and the region of lecithin concentrations of less than $20 \%$ by weight. In said area, samples with Acid S40P/Lecithin ratios of 9 and 20 were studied. These concentrations were chosen because they are found within the region that can generate the formation of the micellar phase, as the system has the characteristics of a transparent phase (as seen in Figure 2 in the magnified region) of low viscosity and isotropy.

When the content of Acid S40P and progressively the content of lecithin (green region) increase, there is a macroscopic multi-phase region of dispersions with indeterminate milky liquid yellow appearance, with a macroscopic appearance like that seen in Figure 3a. The sample was observed to be 50\% Acid S40P, 33\% lecithin, and $17 \%$ water by weight using a polarizing microscope (see sample 20 shown in Figure 3a regarding solubilization at an Acid S40P/lecithin ratio of 1.5) This sample was chosen to represent the multi-phase region where New phases may form due to higher contents of lecithin and the tendency of this lipid to form liposomes.

Figure $3 \mathrm{~b}$ and $3 \mathrm{c}$ show the microphotographs taken of the areas indicated by the arrows, which are the homogeneous intermediate and the turbid upper foam zones,

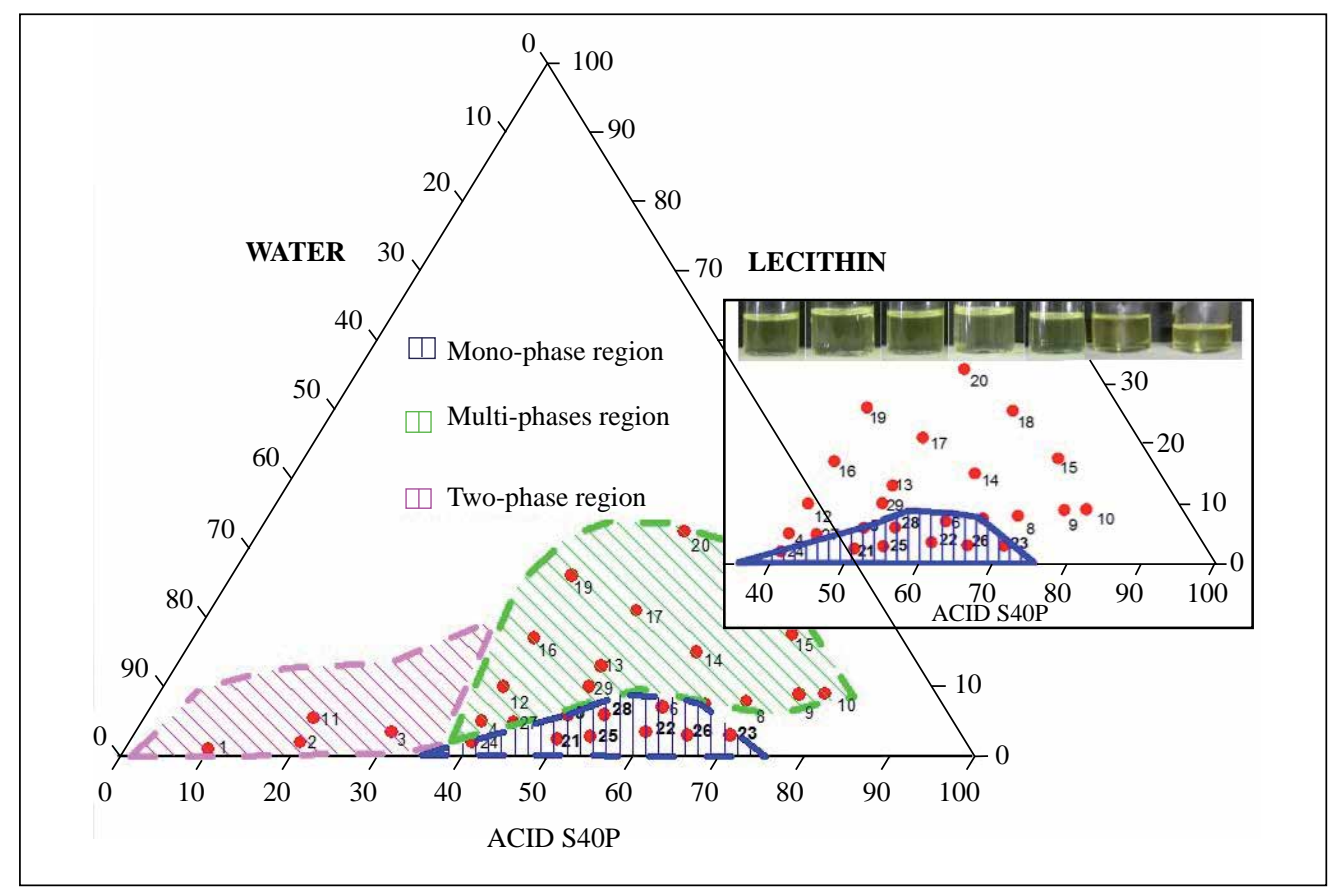

Figure 2. Diagram of the ternary phases of the Acid S40P/lecithin/water system at a $30.0 \pm 0.1^{\circ} \mathrm{C}$. The concentrations are shown in percentage by weight $(\% \mathrm{~W})$. The areas shown in in color were determined using direct visual observation. The red dots indicate samples prepared for study at different degrees of dilution. The blue area in the magnified image corresponds to the single-phase region of the micelles, which was the subject of study. 
respectively. The presence of a lamellar phase dispersed in an isotropic phase was confirmed. The Maltese crosses (refer to the area inside the green circle in Figure 3b for details) and the mosaic birefringent areas (see Figure 3c) are distinct characteristics of a lamellar structure (Cox and Merz, 1958). Montalvo, et al., (2013) determined the regions and the various structures that form in the Acid S40P/lecithin/water system, creating a broader range of concentrations in the phase diagram for higher contents of soy lecithin than those presented in this study.

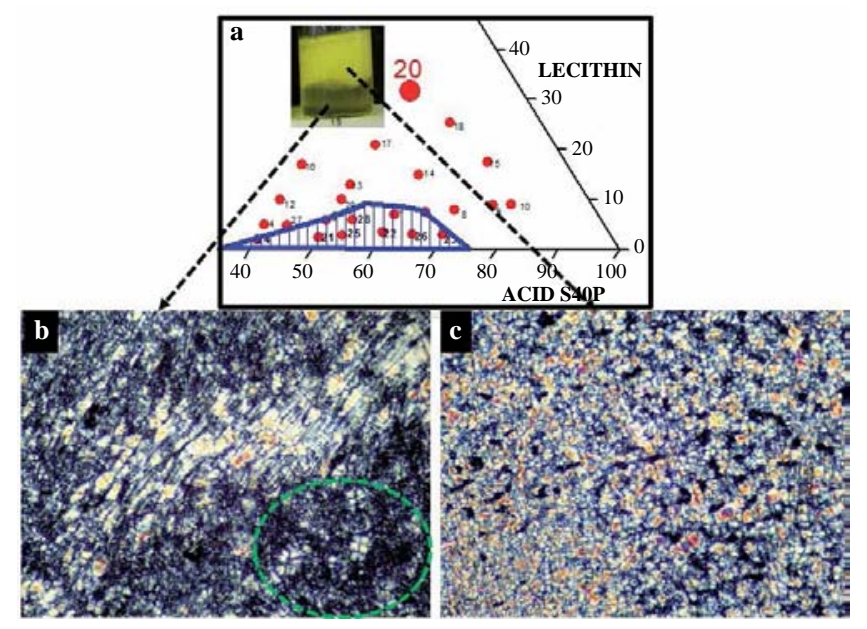

Figure 3. a) Location of sample 20 in the ternary diagram, containing 50\% Acid S40P and 33\% lecithin, which displays multiple phases separated macroscopically. b) Photograph taken of the intermediate homogeneous phase of sample 20 shown in part a. c) Photograph of the turbid upper foam zone of sample 20 shown in part a. The photographs were taken using an optical microscope with crossed polarizers at a magnification of $10 \mathrm{X} / 0.25$.
Determination of viscoelastic behavior. To examine and compare the changes in viscoelasticity, flow tests were performed on the systems that are the subject of this study, namely Acid S40P/water and Acid S40P/lecithin/ water. Samples from both systems that presented a stable homogeneous phase were studied. In Figure 4, the curves corresponding to the samples of the binary system Acid S40P/water are shown. In each case, newtonian behavior was present, with viscosity being independent of the gradient of the shear velocity. The viscosity values that were estimated presumably correspond to the micellar aggregates in the aqueous solutions due to the data found regarding the $\mathrm{CMC}$ using the surface tension method and due to the display of newtonian behavior. Thus, the existence of aggregates of spherical structure in the aqueous solution is proposed.

To evaluate the effects of the surfactant on viscosity, the viscosity values are presented as a function of the percentage of polymer composition. In Figure $4 \mathrm{~b}$, the viscosity at a shear velocity of zero significantly increases as the content of S40P increases, up to a value of $50 \%$ by weight. The existence of a maximum can be attributed to the presence of a large number of aggregates and an increase in size. If the micelles are large enough to be highly flexible at the maximum concentration value, viscosity will decrease. The same behavior was found in microemulsions with HMPEG (Karlsson, et al., 1999) and for micelles in systems with surfactants (Karlsson, et al., 1999; Antunes, et al., 2003; Montalvo, et al., 2003). Continually increasing the surfactant content (Acid S40P) resulted in an abrupt decrease in the viscosity up to a composition of $70 \%$ surfactant. The decrease in viscosity as a result of an increase in concentration has been reported in aqueous solutions with end-capped PEG polymers (Cox \& Merz, 1958). At a value

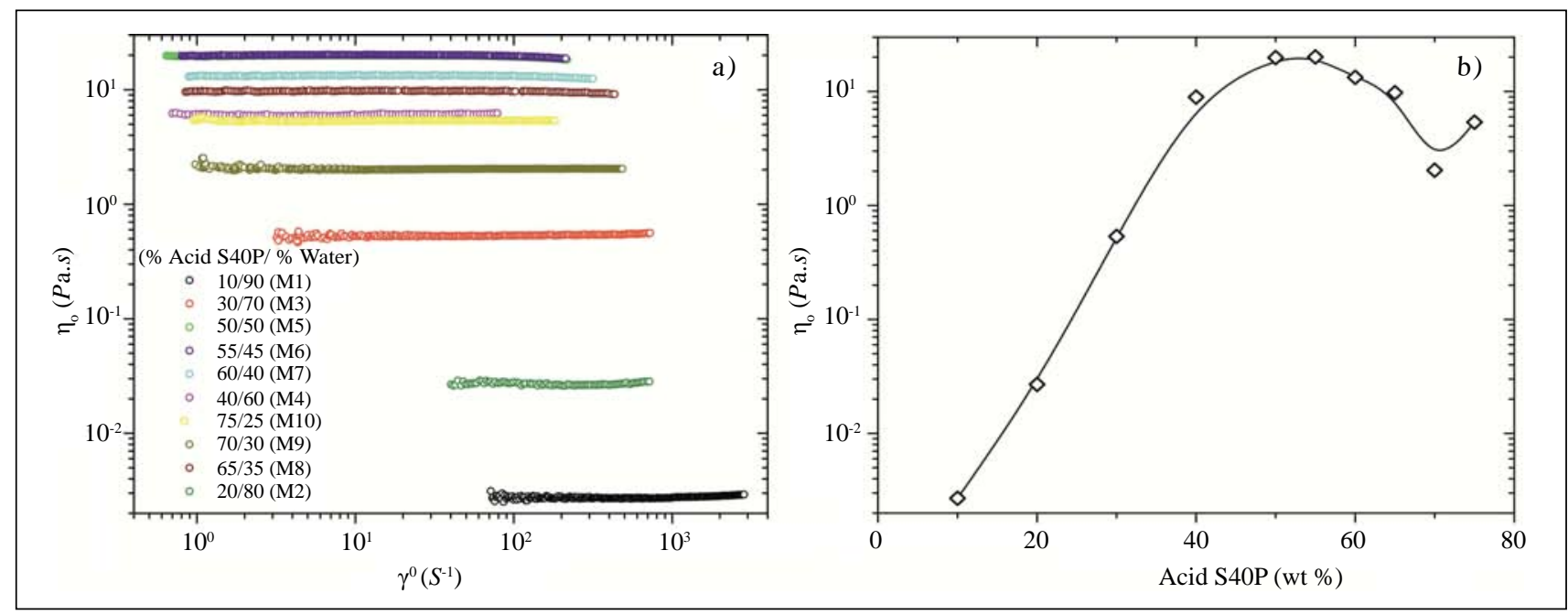

Figure 4. Flow tests of samples that presented a stable and homogeneous phase for the Acid S40P-water system. a) Logarithmic graph of viscosity as a function of shear velocity at $30^{\circ} \mathrm{C}$. Corrections have been made to adjust for inertia; b) Logarithmic graph of the viscosity values as a function of the percent content of Acid S40P at $30^{\circ} \mathrm{C}$ for each of the samples. The regression line is for visual reference only. Figure partially modified with permission from Montalvo, et al., (2013). 
of $75 \%$ surfactant content, viscosity begins to increase once again, probably because this is the limit of the region where turbid multiphase samples form.

The samples in the blue area of Figure 2 corresponding to the single-phase homogeneous and stable system S40P/ lecithin/water with Acid S40P/lecithin ratios of 9 and 20 were also studied. In the stipulated conditions of the experiments, the behavior shown in Figure 5a was observed, where samples with a $65 \%$ Acid S40P content (sample 26) and a $70 \%$ Acid S40P content (sample 23) act as newtonian fluids, while all other samples displayed a pseudoplastic behavior, that is to say, their viscosity is initially constant, but decreases as the gradient of the shear velocity increases.

Regarding the samples with pseudoplastic behavior, the high values of viscosity and the dependency of the viscosity upon the gradient of the shear velocity are indications that the aggregates in the aqueous solution were elongated (Karlson, et al., 1999; Shikata, et al., 1988; Rehage \& Hoffmann, 1991; Clausen, et al., 1992). Initially, the constant viscosity value (newtonian regime) is due to the randomly distributed elongated aggregates, but when a shear stress is applied to these aggregates, they tend to orient themselves in the direction of the flow, resulting in a decrease in viscosity. The lower the gradient of the shear velocity produced by the decrease in viscosity, the more flexible the micelles, which can therefore orient themselves more easily.

The samples that displayed newtonian behavior had a high viscosity value when compared to those of the Acid $\mathrm{S} 40 \mathrm{P} /$ water system with the same proportion of polymers, and also possessed newtonian characteristics. Although there is no clear evidence of the formation of a cylindrical micelle structure for these systems, it is possible that the aggregates were already elongated, but were smaller in size, meaning that in order to orient themselves in the direction of the flow they would require higher shear velocities.

Figure $5 \mathrm{~b}$ shows that as the viscosity (newtonian regime values) increased, it reached a maximum of $50 \%$ and then decreased in relation to the Acid S40P/lecithin up until a value of $70 \%$. When comparing these results to those shown in figure $4 \mathrm{~b}$, the same behavior is observed. The rise in viscosity can be explained by an increase in the size of the aggregates in the solution and their greater flexibility, corroborated by a lower critical shear velocity value at which the drop in viscosity occurs (Figure $5 a$ ). When the surfactant content is above $50 \%$, viscosity decreases (Cortes, et al., 1999). The open dots on the graph have a higher lecithin content than those represented by the closed dots. The different values evidence the interaction of the lecithin with the Acid S40P.

Both moduli $G^{\prime}$ and $G^{\prime \prime}$ increase with the angular frequency predicted using Maxwell model 2 and 1, respectively (see Figure 6b). Although the Maxwell model predicts that at a high angular velocity, the value of the storage modulus will reach a plateau, while the loss modulus reaches a maximum. This did not occur within the range of frequencies that were observed. The moduli $G^{\prime}$ and $G^{\prime \prime}$ were adjusted simultaneously using the equations of the Maxwell model, where the relaxation time $\tau$ and the plateau value for $G_{0}$ are the only adjustment parameters. The obtained relaxation time values were $9.5( \pm 0.5) \mathrm{ms}$ and $4.8( \pm 0.2)$ $\mathrm{ms}$ for the samples with a $50 \%$ and $54 \%$ Acid S40P content by weight respectively. These values are of the same order of magnitude as those of micelles in viscoelastic rod form (Khromova, et al., 2001).

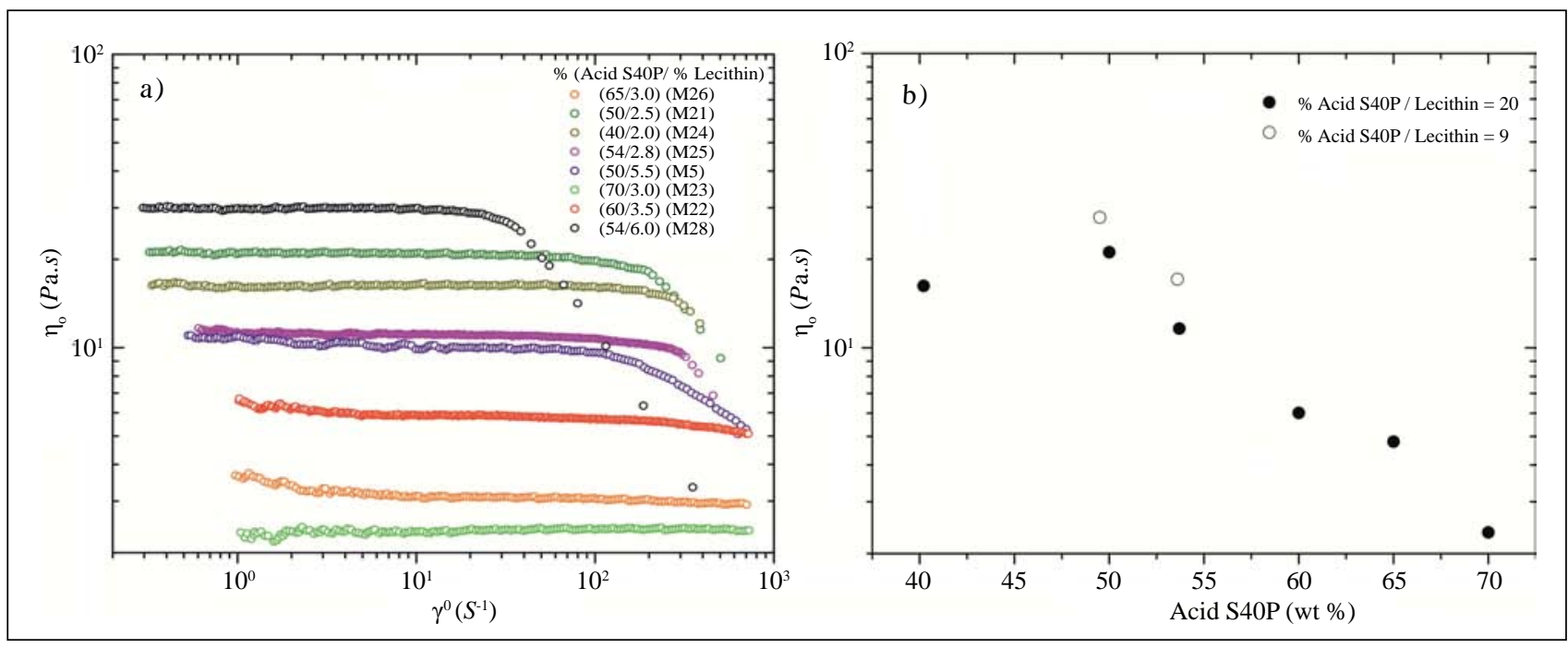

Figure 5. Flow tests of samples that presented a stable and homogeneous phase for the Acid S40P/lecithin/water system. a) Logarithmic graph of viscosity as a function of the shear velocity at $30^{\circ} \mathrm{C}$. Corrections have been made to adjust for inertia. b) Logarithmic graph of the viscosity of the newtonian regime as a function of the percent content of Acid S40P at $30{ }^{\circ} \mathrm{C}$. The black dots $\left(\bullet^{\bullet}\right)$ correspond to the Acid $\mathrm{S} 40 \mathrm{P} /$ lecithin=20 line, and the white dots (o) correspond to the Acid S40P/lecithin=9 line. 


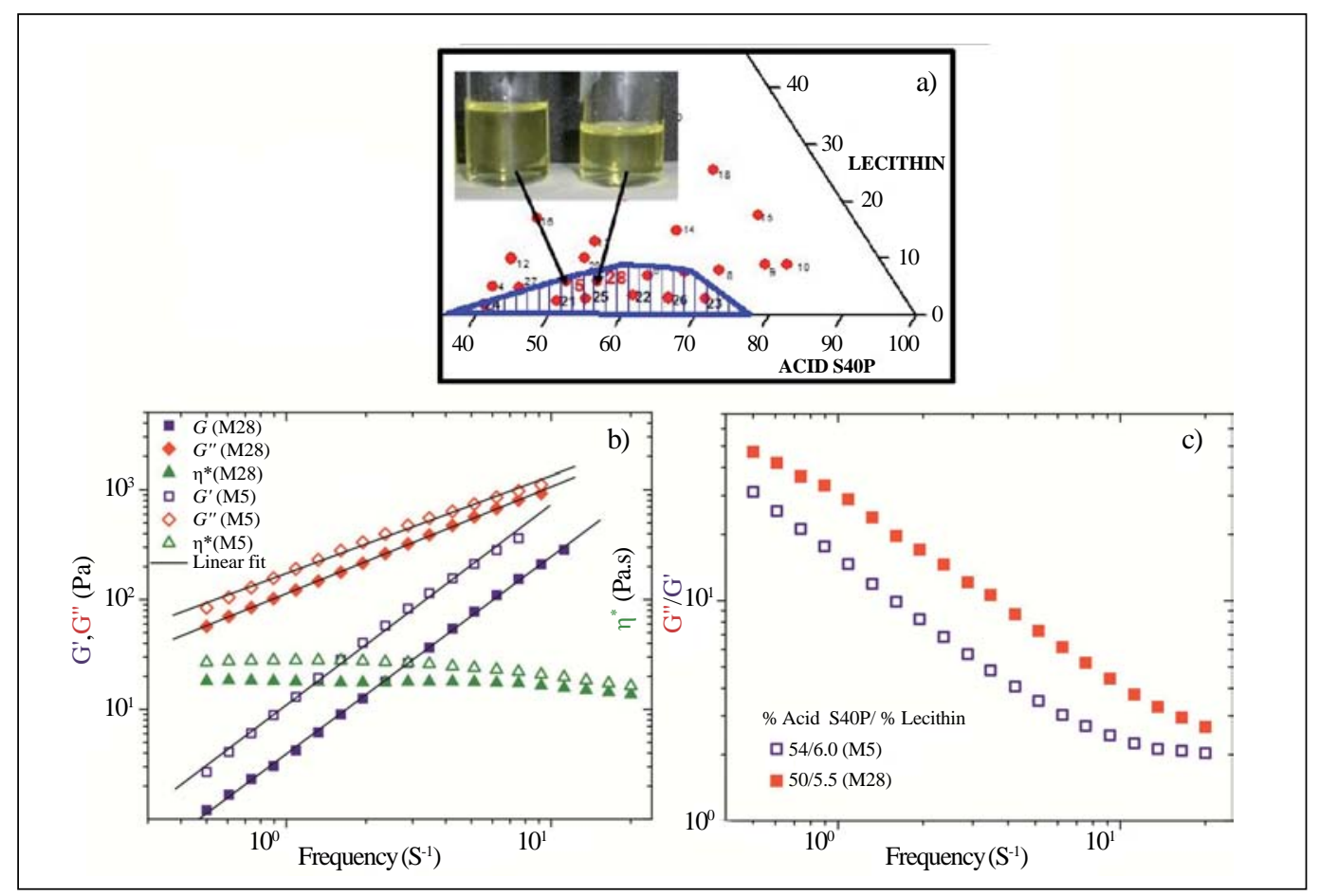

Figure 6. Oscillatory tests for the samples of the stable single-phase micellar region of the phase diagram of the S40P/lecithin/water system. a) Section of the phase diagram that indicates the samples measured and their macroscopic appearance: samples of 50\% Acid S40P/5.5\% lecithin and 4\% Acid S40P/6\% lecithin compositions. b) The complex viscosity modulus ( $\left.\eta^{*}\right)$, the elastic modulus, and the viscous modulus versus the frequency of oscillation obtained by applying amplitudes of $\sigma=4 \mathrm{~Pa}$ (sample 5) and $3.5 \mathrm{~Pa}$ (sample 28) at an interval of frequencies from 0.5 to $20 \mathrm{~Hz}$ for the two samples. b) Loss tangents (defined as $\mathrm{G} /$ ) versus the frequency of oscillation for said samples.

For the purposes of comparing the elasticity of each of the samples, the loss tangent has been plotted against the frequency of the oscillation (Figure 6c). The loss tangent is a dimensionless parameter defined as the ratio of the loss or viscous modulus $G^{\prime \prime}$ and the storage or elastic modulus $G^{\prime}$.

In examining Figure 6, it is observed that the loss tangent continuously decreases as the frequency increases, with a slope of approximately -1 , in accordance with Maxwellian behavior. All of its values are greater than 1 , which indicates a greater viscosity than elasticity in the samples (Montalvo, et al., 2003). In this particular case, the sample of composition 50\% Acid S40P/5.5\% lecithin (sample 28) has higher tangent loss values than those of the sample of composition 54\% Acid S40P/6\% lecithin (sample 5), which means that the highest elastic contribution is found in sample 5 , whose composition was 54\% Acid S40P/6\% lecithin.

\section{Conclusion}

The formation of multiple phases is possible in systems with hydrophobically modified polymers, as evidenced by the ternary phase diagram presented for Acid S40P/lecithin/ water. The use of a phospholipid mixture augments the complexity of the system and its number of degrees of freedom.

In some cases, various macroscopically separated coexistent phases were observed, emphasizing the lack of homogeneity in certain regions. A micellar region forms in this system that has been characterized through the determination of the CMC of the micelles of Acid S40P in water and by measuring viscosity. The samples of the Acid S40P/water system acted as newtonian fluids, which suggests that their micelle formations tend to be spherical. When linking the viscosity values obtained for each of the samples to the Acid S40P value in percent by weight, a decrease in viscosity is observed when the content of Acid S40P exceeds $50 \%$. This may be due to a gradual change at the molecular level from a structure that contains micellar aggregates that are interconnected via polymer bridging to a more molten state where the hydrophilic and hydrophobic microaggregation is less pronounced.

When the soy lecithin was added to the Acid S40P/water system, it was concluded that it interacted with the Acid $\mathrm{S} 40 \mathrm{P}$, and that the nature of the interaction was probably hydrophobic. The majority of the samples behaved as pseudoplastic fluids. Initially, the constant viscosity value (newtonian regime) is due to the randomly distributed elongated aggregates, but when a shear stress is applied to these aggregates, they tend to orient themselves in the direction of the flow, resulting in a decrease in viscosity. The viscosity of the newtonian regime increases with the content of Acid S40P, but as is the case with the system that does not contain lecithin, the viscosity decreases when the Acid S40P content is above $50 \%$. With respect to the behavior 
of the samples analyzed in the oscillatory tests, the viscous modulus $G^{\prime \prime}$ was greater than the elastic modulus $G^{\prime}$. This behavior is consistent with the Maxwell model.

\section{Acknowledgments}

The authors are grateful to Professor Michael Gradzielski forcontacting Evonic Goldschmidt $\mathrm{GmbH}$, who supplied us withthe TEGO Acid S40P reagent and M. Diaz is grateful for her scholarship to the Agencia Española de Cooperación Internacional para el Desarrollo (AECID), Universidad de Alcalá and Banco Santander, through the "Becas Miguel de Cervantes Saavedra” Program.

\section{Conflict of interest}

Author declare do not have any conflict of interest about the content of the article.

\section{References}

Antunes, F., Thuresson, K., Lindman, B., Miguel, M. 2003. Rheological investigation of the association between a nonionic microemulsion and hydrophobically modified PEG influenpolymer architecture. Colloids and Surfaces, A. 15: 87-100.

Bartucci R., Montesano G., Sportelli L. 1996. Effects of poly(ethylene glycol) on neutral lipid bilayers. Colloids and Surfaces, A. 115: 63-71.

Clausen, T. M., Vinson, P. K., Minter, J. R., Davis, H. T., Talmon, Y., Miller W. G. 1992. Viscoelastic micellar solutions: microscopy and rheology. The Journal of Physical Chemistry. 96: 474-484.

Cortes, A. B., Valiente, M., Rodenas, E. 1999. Properties of the L and lyotropic phases in CTAB/ Glycerol/ water and CTAB/ Glyceraldehyde/ water systems. Langmuir. 15 (20): 66586663.

Cox, W. P., Merz, E. H. (1958). Rheology of polymer melts. A correlation of dynamic and steady-flow measurement. Journal of Polymer Science. 28: 619-622.

Goddard, E. D. Ananthapadmanaban, K. P. 1993. Interactions of Surfactants with Polymer and Proteins. CRC Press, Boca Raton, FL.

Hoffmann, H. 1994. Viscoelastic surfactant solutions In: Structure and flow in surfactant solutions. Herb, C. A., Prud'homme, R. K., Eds. ACS Symposium Series 578; Washington, DC: American Chemical Society.

Jonsson, B., Lindman, B., Holmberg, K., Kronberg, B. 1998. Surfactants and Polymers in Aqueous Solution. John Wiley \& Sons, London.

Karlsson, L., Nilsson, S., Thuresson, K. 1999. Rheology of an aqueous solution of an end-capped polyethylene glycol) polymer at concentration. Colloid Polymers Science. 277: 798-804.
Khan, A., Zhang, K. W., Mendoca, C. 1994. Solubilization of nonionic polymers in a lyotropic lamellar mesophase: Lecithin-water-polyethylene oxide system. Journal of Colloid and Interface Science. 165: 253-255.

Khromova, Yu L., Shumilina, E.V., Shchipunov, Yu. A. 2001. Lecithin organogels containing poly (ethylene glycol) monolaurate. Colloid Journal. 63 (2): 242-247.

Koynova, R., Tenchov, B. 2001. Interactions of surfactants and fatty acids with lipids. Current Opinion in Colloid \& Interface Science. 6: 277-286.

Kwak, J. C. T. 1998. Surfactant Science Series. Vol. 77: PolymerSurfactant Systems, Marcel Dekker, New York.

Li X., Lin X., Zheng L., Yu, L., Lv F., Zhang Q., Liu W. 2008. Effect of poly(ethyleneglycol) stearate on the phase behavior of monocarate/tween $80 /$ water system and characterization of poly(ethylene glycol) stearate-modified solid lipid nanoparticles. Colloids and Surfaces, A. 317: 352-359.

Montalvo, G., Rodenas, E., Valiente, M. 2003. Effects Cetylpyridinium Chloride on phase and rheological behavior diluted $\mathrm{C}_{12} \quad \mathrm{E}_{4} /$ Benzyl Alcohol/water system. Journal of Colloid and Interface Science. 227: 171-175.

Montalvo, G., Pons, R., Zhang, G., Díaz, M., Valiente, M. 2013. Structure and Phase Equilibria of the Soybean Lecithin/PEG 40 Monostearate/Water System. Langmuir. 29: $14369-14379$.

Naumann, C. A., Brook, C. F., Fuller, G. G., Lehmann, Ruhe, J., Knoll, W., Kuhn, P., Nuyken, O., Frank, C. W. 2001. Two dimensional physical networks of lipopolymers at the air/water interface: Correlation of molecular structure and surface rheological behavior. Langmuir. 17: 2801-2806.

Nikolova, A. N., Jones, M. N. 1998. Phospholipid free thin liquid films with grafted poly(ethylene glycol)-200: Formation, interaction forces and phase states. Biochimica et Biophysica Acta, Biomembranes. 1372: 237-243.

Rehage, H., Hoffmann, H. 1991. Viscoelastic surfactant solutions: model systems for rheological research. Molecular Physics: An International Journal at the Interface between Chemistry and Physics. 74: 933-973.

Shikata, T., Hirata, H., Kotaka, T. 1988. Micelle formation of detergent molecules in aqueous media. 2. Role of free salicylate ions on viscoelastic properties of aqueous cetyltrimethylammonium bromide-sodium salicylate solutions. Langmuir. 42: 354-359.

Torchelin, V. P. 2002. PEG-based micelles as carriers of contrast agents for different imaging modalities. Advanced Drug Delivery Reviews. 54: 235-252.

Xia, Q., Hao, X., Lu, Y., Xu, W., Wei, H., Ma, Q., Gu, N. 2008. Production of drug-loaded lipid nanoparticles based on phase behaviors of special hot microemulsions. Colloids and Surfaces, A. 313-314: 27-30.

Xia, Q., Xu, D., Lu, Y., Xu, F., Tang, J., Gu, N. (2009). Preparation and characterization of drug-loaded lipid nanoparticles. Journal of Scientific Conference Proceedings. 1: 300-302. 